\title{
Antidepressive Therapy Has No Effect on Ciliary Neurotrophic Factor Concentration in Blood Serum of Patients with Melancholic Depression
}

\author{
Uzbekov $\mathbf{M}^{1 *}$, Shikhov $\mathbf{S}^{1}$, Syrejshchikova $\mathrm{T}^{2}$ and Brilliantova $\mathbf{V}^{1}$ \\ ${ }^{1}$ Moscow Research Institute of Psychiatry, Moscow, Russia \\ ${ }^{2}$ Lebedev Physical Institute, Moscow, Russia
}

*Corresponding author: Uzbekov M, Moscow Research Institute of Psychiatry, Head of the Laboratory of Brain Pathology,

Moscow, Russia

\section{ARTICLE INFO}

Received: 幽 December 14, 2020

Published: 幽 December 23, 2020

\section{ABSTRACT}

Keywords: Cliliary Neurotrophic Factor; Melancholic Depression; Venlafaxine; Blood Brain Barrier

Citation: Uzbekov M, Shikhov S,

Syrejshchikova T, Brilliantova V.

Antidepressive Therapy Has No Effect on

Ciliary Neurotrophic Factor Concentration

in Blood Serum of Patients with Melancholic

Depression. Biomed J Sci \& Tech Res 32(5)-

2020. BJSTR. MS.ID.005306.

\section{Introduction}

Ciliary neurotrophic factor (CNTF) is a $22-\mathrm{kDa}$ cytokine belonging to the interleukin- 6 family and is mainly expressed in glial cells of the central and peripheral nervous systems. CNTF plays an important role in the regulation of neuronal development, neuroprotection and may influence cognitive processes [1]. The physiological relevance of circulating CNTF still needs to be established. The role of the glial cells and glio-neuronal interaction in the pathogenetic mechanisms of mental disorders is poorly investigated in spite that in the last decade it was established that glial cells have a very important meaning in the functioning of the central and peripheral nervous systems [2]. Depression became a large medical - social problem that can only become worse during next years. Therefore, the comprehensive study of depression and the pathogenetic mechanisms of this disease becomes one of the main tasks of medical science. Depression is characterized by the disturbances of monoamine and cytokines metabolism.

It was established that different neurotrophic factors can influence on the affective behavior, including depression, anxiety and melancholy [3]. There is information about the investigation of CNTF concentration in the blood in healthy persons and in patients with rheumatoid arthritis, myeloma and different neurologic diseases [4]. But there are no reports in the literature regarding the circulating levels of CNTF in depression the aim of the study was to investigate CNTF levels in blood serum in patients with melancholic depression (MD) under antidepressive therapy.

\section{Materials and Methods}

There were investigated 27 patients with MD in the clinic of affective disorders of Moscow Research Institute of Psychiatry and 11 healthy volunteers. The patient's state according to ICD-10-CM criteria [International Classifications of Diseases, tenth edition, clinical modification (ICD-10-CM)] was defined as a depressive episode in the frame of bipolar depressive disorder (type 2) (F32) and in the structure of recurrent depressive disorder (F33) [5]. Investigation was performed under conclusion of local ethical committee of Institute (№ 16 of 13.03.2017). Patients state was evaluated using the Hamilton Rating Scale for depression (HAM-D) 
(21 items) and the Hamilton Rating Scale for anxiety (HAM-A) [6]. CNTF concentration in the blood serum was estimated at the admission and after 30 days of pharmacotherapy using venlafaxine in the dose of $75-150 \mathrm{mg} /$ day. CNTF concentration in blood serum was measured by ELISA method using "Human Ciliary Neurotrophic Factor (hCNTF) ELISA kit” (Cusabio Technology LLC, USA). Statistical analysis was performed using Wilcoxon-MannWhitney u-test. Difference was considered as significant at $\mathrm{p}=0.05$.

\section{Results and Discussion}

At admission the total score according to HAM-D was $23.5 \pm 5$.8 which is consistent with severe depressive disorder whereas according to HAM-A a total score was $18.3 \pm 5.9$ that corresponded to moderate anxiety. Before treatment CNTF concentration in blood serum of patients with MD was $679.11 \pm 63.09 \mathrm{pg} / \mathrm{ml}$ of serum. It was significantly for $71.7 \%$ higher in comparison with healthy subjects (405.96 $\pm 91.91 \mathrm{pg} / \mathrm{ml}$ of serum, $\mathrm{p}=0.01)$. After 30 days of venlafaxine therapy there were considerable improvement of the patient's state - total score were equal to 6.2 и 6.1 according to HAM-D and HAM-A, respectively ( $p=0.003$ in comparison with the score before treatment). But venlafaxine therapy has to effect on CNTF concentration in blood serum of MD patients. CNTF concentration practically was on the level characteristic for patients at admission $(679.1 \pm 63.1$ and $732.2 \pm 126.5 \mathrm{pg} / \mathrm{ml}$ of serum before and after the pharmacotherapy, respectively). It was shown that depression is followed by the increased permeability of blood-brain barrier [7]. We can hypothesize that in pathological condition CNTF is synthesized and secreted in the brain in larger amounts, but it does not exhibit neuroprotective properties because it immediately leaks out into the blood stream through the damaged blood-brain barrier [7].

\section{Conclusion}

1) It is shown the first time in the literature that depression, in particular MD, is followed by disturbed CNTF metabolism.

2) CNTF cannot reveal its neuroprotective functions in the brain because of immediate leakage through damaged bloodbrain barrier in blood stream.

3) The results of our investigation point out on the necessity of inclusion in the therapeutic process of drugs that can restore blood-brain barrier properties.

\section{References}

1. Sedtner M, Carroll P, Holtmann B, Hughes RA, Thoenen H (1994) Ciliary neurotrophic factor. J Neurobiol 25(1): 1436-1453.

2. Verkhratsky A, Butt AM (2013) Glial Physiology and Pathophysiology. Wiley-Blackwell pp. 560.

3. Peruga I, Hartwig S, Merkler D, Thöne J, Hovemann B, et al. (2012) Endogenous ciliary neurotrophic factor modulates anxiety and depressive-like behavior. Behav Brain Res 229(2): 325-332.

4. Brondino N, Rocchetti M, Fusar Poli L, Damiani S, Goggi A, et al. (2018) Increased CNTF levels in adults with autism spectrum disorders. World J Biol Psychiatry 19: 1-5.

5. (2015) World Health Organization. International Classification of Diseases and Related Problems. (10 ${ }^{\text {th }}$ edn) Clinical Modification, WHO, Geneva, Switzerland.

6. Bech P (1999) Acute therapy of depression. J Clin Psychiat 54: 19-26.

7. Morris G, Fernandes BS, Puri BK, Walker AJ, Carvalho AF (2018) Leaky brain in neurological and psychiatric disorders: Drivers and consequences. Aust N Z J Psychiatry 52(10): 924-948.

\section{ISSN: 2574-1241}

DOI: $10.26717 /$ BJSTR.2020.32.005306

Uzbekov M. Biomed J Sci \& Tech Res

This work is licensed under Creative Commons Attribution 4.0 License

Submission Link: https://biomedres.us/submit-manuscript.php

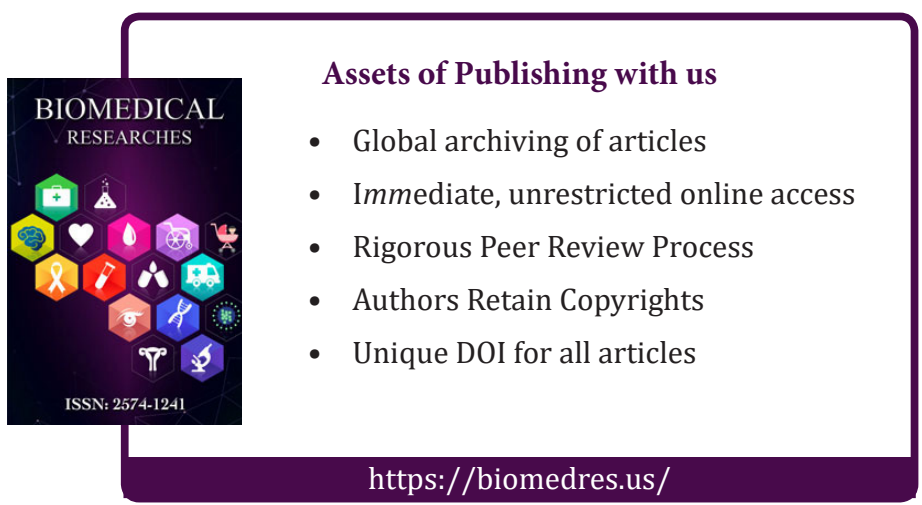

